\title{
Polymorphisms in monolignol biosynthetic genes are associated with biomass yield and agronomic traits in European maize (Zea mays L.)
}

\author{
Yongsheng Chen ${ }^{1,2 \dagger}$, Imad Zein ${ }^{3 \dagger}$, Everton Alen Brenner ${ }^{1}$, Jeppe Reitan Andersen ${ }^{4}$, Mathias Landbeck ${ }^{5}$,
} Milena Ouzunova ${ }^{5}$, Thomas Lübberstedt ${ }^{1 *}$

\begin{abstract}
Background: Reduced lignin content leads to higher cell wall digestibility and, therefore, better forage quality and increased conversion of lignocellulosic biomass into ethanol. However, reduced lignin content might lead to weaker stalks, lodging, and reduced biomass yield. Genes encoding enzymes involved in cell wall lignification have been shown to influence both cell wall digestibility and yield traits.

Results: In this study, associations between monolignol biosynthetic genes and plant height (PHT), days to silking (DTS), dry matter content (DMC), and dry matter yield (DMY) were identified by using a panel of 39 European elite maize lines. In total, 10 associations were detected between polymorphisms or tight linkage disequilibrium (LD) groups within the COMT, CCOAOMT2, 4CL1, 4CL2, F5H, and PAL genomic fragments, respectively, and the above mentioned traits. The phenotypic variation explained by these polymorphisms or tight LD groups ranged from $6 \%$ to $25.8 \%$ in our line collection. Only $4 C L 1$ and F5H were found to have polymorphisms associated with both yield and forage quality related characters. However, no pleiotropic polymorphisms affecting both digestibility of neutral detergent fiber (DNDF), and PHT or DMY were discovered, even under less stringent statistical conditions.

Conclusion: Due to absence of pleiotropic polymorphisms affecting both forage yield and quality traits, identification of optimal monolignol biosynthetic gene haplotype(s) combining beneficial quantitative trait polymorphism (QTP) alleles for both quality and yield traits appears possible within monolignol biosynthetic genes. This is beneficial to maximize forage and bioethanol yield per unit land area.
\end{abstract}

\section{Background}

Elevating the polysaccharide to lignin ratio is one possible approach to improve the quality of biofeedstocks for ethanol conversion [1]. It is believed that cell wall lignin content is negatively correlated with forage digestibility [2] and bioethanol production [3]. Removing lignin by oxidative pretreatment could significantly increase the release of available sugars in subsequent enzyme hydrolysis compared to the untreated control [4]. In maize, a $1 \%$ increase in available cellulose is expected to increase the potential ethanol production from 101.6 to 103.3 gallons per dry ton of biomass, as calculated using the U.S. Department of Energy's Theoretical Ethanol Yield

\footnotetext{
* Correspondence: thomasl@iastate.edu

+ Contributed equally

'Department of Agronomy, lowa State University, Ames, lowa 50011, USA
}

Calculator and Feedstock Composition Database [5]. Theoretical maximum ethanol yields from biomass are highly correlated $\left(r^{2}=0.9\right)$ with acid detergent lignin concentration [6]. According to Lorenz et al. [1], variation in ethanol yield is driven by glucan convertibility, which is highly correlated with ruminal digestibility and lignin content. Besides the lignin content, other aspects of cell wall lignification like the ratio of syringyl to guaiacyl lignin units affect cell wall digestibility $[7,8]$ and, therefore, likely ethanol production from biofeedstocks. The syringyl to guaiacyl ratio impacts the efficiency of cell wall hydrolysis in forage sorghums [9]. In summary, modification of cell wall lignification is a promising route to improve the quality of bioenergy crops.

However, reduced lignin content can influence the overall plant performance. Generally, reduced lignin content results in weaker stalks, reduced stover and 
grain yield, and delayed maturity [10]. In maize, brownmidrib (bm) mutants show a decreased lignin content and increased cell wall digestibility [11]. For instance, lignin content is reduced by one third and cell wall digestibility is increased by $9 \%$ in $b m 3$ lines or hybrids [12]. However, maize $b m$ lines or hybrids show reduced vigor during vegetative growth, a high incidence of stalk breakage at maturity, and decreased grain and stover yield [13-16]. Similarly, $b m$ hybrids of Sudan grass and sorghum also show reduced dry matter yield $[17,18]$. Genetically engineered tobacco with reduced CCOAOMT [19] or $P A L$ activities [20], poplar with down-regulated $C C R$ activity [21], Arabidopsis with a mutation in the CCR1 [22], C3H [23], and C4Hgenes [24], or with double mutations in the COMT1 and CCoAOMT1 genes [25] showed reduced plant size. By silencing the HCT gene in Arabidopsis, Besseau et al. [26] obtained mutants with modified lignin structure as well as repressed plant growth. Silencing of $H C T$ resulted in redirection of the metabolic flux into flavonoids, which suppressed auxin transport.

Decreased lignin content does not necessarily have negative effects on plant growth. After divergent selection for fiber concentration in maize, Wolf et al. [27] found only weak and inconsistent correlations between lignin content and various agronomic traits. Weller et al. [28] found no yield difference between $b m 3$ and wildtype isolines. He et al. [29] developed $O$-methyltransferase down-regulated maize with a $17 \%$ decrease in lignin content, increased digestibility, without effect on dry matter yield. In aspen, repression of $4 C L$ led to a $45 \%$ reduction in lignin content [30]. While the structural integrity at both the cellular and whole-plant level was not affected, enhanced leaf, root, and stem growth were observed, as well as increased cellulose content [30]. By simultaneously silencing $H C T$ and $C H S$ genes, Besseau et al. [26] obtained normal growing Arabidopsis plants with substantially altered lignin composition. In summary, cell wall lignification is generally, but not always, negatively correlated with biomass yield and other agronomic traits. These correlations can be due to: (1) linkage of genes controlling monolignol biosynthesis and biomass yield, (2) pleiotropy at the level of genes but not QTPs within monolignol biosynthetic genes affecting both groups of traits, and (3) pleiotropic effects of QTP(s) within monolignol biosynthetic genes. The underlying genetic cause(s) for these correlations impact the strategy for breeding of bioenergy crops.

Ten enzymes are involved in converting phenylalanine to monolignols in maize, and the majority is encoded by two or more genes [31]. Four genes encode PAL proteins in Arabidopsis, which catalyze the first step in the phenylpropanoid pathway [32]. In maize, PAL has both phenylalanine and tyrosine ammonia lyase activity [33] and at least five contigs with $P A L / T A L$ annotation were identified [31]. The other enzymes involved in biosynthesis of monomers include cinnamate 4-hydroxylase $(\mathrm{C} 4 \mathrm{H})$, 4-coumarate:CoA ligase $(4 \mathrm{CL})$, hydroxycinnamoyl-CoA transferase (HCT), $p$-coumarate 3-hydroxylase $(\mathrm{C} 3 \mathrm{H})$, caffeoyl-CoA $O$-methyltransferase (CCoAOMT), cinnamoyl-CoA reductase (CCR), ferulate 5 -hydroxylase $(F 5 H)$, caffeic acid $O$-methyltransferase (COMT), and cinnamyl alcohol dehydrogenase (CAD), with at least two, seven, two, one, five, eight, two, one, and seven sequences were identified, respectively [31]. Association mapping is a promising approach to identify candidate QTPs for traits of interest [34-37]. The CCOAOMT2 gene is co-localized with a QTL for cell wall digestibility and lignin content [38], and an 18-bp indel in the first exon was found to be associated with cell wall digestibility [34]. In addition, associations have been identified between neutral detergent fiber (NDF) and polymorphisms within $P A L, 4 C L 1, C 3 H$, and $F 5 H$ genes, between in vitro digestibility of organic matter (IVDOM) and polymorphisms within PAL, 4CL1, and $\mathrm{C} 3 \mathrm{H}$, and between digestibility of neutral detergent fiber (DNDF) and polymorphisms in $\mathrm{C} 3 \mathrm{H}$ and $\mathrm{F} 5 \mathrm{H}$ genes $[35,36]$. However, genes encoding any of these 10 enzymes have so far not been studied in relation to biomass yield-related traits. In this study, the relationship between 10 monolignol biosynthetic genes belonging to eight enzyme encoding genes or gene families and the biomass yield-related traits: plant height (PHT), days to silking (DTS), dry matter content (DMC), and dry matter yield (DMY) were analyzed. Only one or two gene member(s) of each gene family were amplified. Our objectives were to investigate, (1) whether candidate quantitative trait polymorphisms (QTPs) for these four traits can be identified in monolignol biosynthetic genes, and (2) whether candidate QTPs for biomass yieldrelated traits and cell wall digestibility traits act pleiotropically by comparing the results of this study with results from previous forage trait association studies [[35,36], Brenner et al.: Polymorphisms in O-methyltransferase genes are associated with stover cell wall digestibility in European maize (Zea mays L.), submitted]. The results are discussed with respect to implications for breeding of maize for forage and lignocellulosic ethanol production.

\section{Results}

\section{Phenotypic data analyses}

Mean phenotypic values for individual lines across four environments ranged from 109.3 to $197.1 \mathrm{~cm}$ for PHT, 68.5 to 85.7 days for DTS, $23.2 \%$ to $36.0 \%$ for DMC, and 2.5 to $8.4 \mathrm{t} / \mathrm{ha}$ for DMY. Overall mean values were 152.0 $\mathrm{cm}, 78.6$ days, $28.5 \%$, and $5.3 \mathrm{t} / \mathrm{ha}$, respectively, for these four traits (Table 1). Variance components for genotype 
and interactions between genotype and environment were significant $(\mathrm{P}=0.01)$ and variance components for environment were significant $(\mathrm{P}=0.01)$ for PHT, DTS, and DMC. Heritabilities were 88.0\%, 92.0\%, 85.7\%, and 81.9\% for PHT, DTS, DMC, and DMY, respectively (Table 1). Means of dent lines were significantly higher than means of flint lines for DTS $(P=0.01)$, DMY $(P=0.01)$, and PHT $(P=0.05)$, whereas DMC was not significantly different between dent and flint lines.

PHT was positively correlated with DTS and DMY at both phenotypic and genotypic levels, with phenotypic and genotypic correlation coefficients ranging from $\mathrm{r}=$ $0.62(\mathrm{P}=0.01)$ to $0.69(\mathrm{P}=0.01)$. DNDF was negatively correlated with PHT (phenotypic correlation coefficient $r_{p}=-0.45$, genotypic correlation coefficient $r_{g}=-0.47, P$ $=0.01)$, as well as DMY $\left(r_{\mathrm{g}}=-0.24, \mathrm{P}=0.05\right)($ Table 2$)$.

Previous studies reported the haplotype diversity of these ten monolignol biosynthetic genes [[35,36,39], Brenner et al:: Polymorphisms in $O$-methyltransferase genes are associated with stover cell wall digestibility in European maize (Zea mays L.), submitted]. The number of haplotypes ranged from 2 to 12 for the ten monolignol biosynthetic genes (see Additional file 1). COMT, CCOAOMT1, and $F 5 H$ showed the largest phenotypic ranges among haplotype classes for PHT (121.2-171.4 $\mathrm{cm})$ and DMC (23.2\%-30.3\%), DMY (4.1-8.4 t/ha), and DTS (72.2-84.1 days), respectively.

\section{Association analyses}

Association analyses revealed that six genes, coding for COMT, CCoAOMT2, 4CL1, 4CL2, F5H, and PAL proteins, were associated with at least one of the four biomass yield-related traits. 10 associations were identified by GLM when including population structure in the analysis and controlling for multiple testing. Among those, seven were validated by MLM (Tables 3 and 4), which, in addition to population structure, corrects for finer scale relative kinship. However, none of these polymorphisms identified by MLM remained significant after controlling for multiple testing by FDR. At the PAL locus a tight LD group containing 17 polymorphisms with $r^{2}=1$ was associated with days to silking (DTS). The 39 lines were classified into two groups by this LD group. The lines including AS1-8, 11-22, 24, and 29 were six days earlier than the remaining lines. This LD group explained 7\% of the total DTS variation in our population. At the $4 C L 2$ locus, a tight LD group consisting of two SNPs (at position 192 and 217) in complete LD explained $14.3 \%$ of the phenotypic variation for PHT. The SNP at position 217 led to an amino acid change. The lines with the TG allele at these two positions were on average $17 \mathrm{~cm}$ higher than the lines with the CA allele. At the CCoAOMT2 locus, three polymorphisms (an indel starting at position 75, two SNPs at position 144 and 406) were in a tight LD group
Table 1 Phenotypic means, variance components, and heritabilities for four agronomic traits across four environments.

\begin{tabular}{|c|c|c|c|c|}
\hline Line & PHT & DTS & DMC & DMY \\
\hline F_AS1 & 109.3 & 70.8 & 36.0 & 3.2 \\
\hline F_AS2 & 154.4 & 75.3 & 27.0 & 3.9 \\
\hline F_AS3 & 136.4 & 76.3 & 25.4 & 5.6 \\
\hline F_AS4 & 150.7 & 71.7 & 25.5 & 4.8 \\
\hline F_AS5 & 121.2 & 71.5 & 28.8 & 2.8 \\
\hline F_AS6 & 151.7 & 78.3 & 29.4 & 4.4 \\
\hline F_AS7 & 141.1 & 74.0 & 27.5 & 4.2 \\
\hline D_AS8 & 137.7 & 74.5 & 29.9 & 4.0 \\
\hline D_AS9 & 179.6 & 84.5 & 27.4 & 8.1 \\
\hline D_AS10 & 168.8 & 85.3 & 29.0 & 7.4 \\
\hline D_AS11 & 159.7 & 82.5 & 25.4 & 5.5 \\
\hline F_AS12 & 145.2 & 80.3 & 30.4 & 3.7 \\
\hline F_AS13 & 150.0 & 80.7 & 30.7 & 4.2 \\
\hline F_AS14 & 171.4 & 79.2 & 23.2 & 5.4 \\
\hline F_AS15 & 152.4 & 77.5 & 29.5 & 4.1 \\
\hline F_AS16 & 128.2 & 72.5 & 26.9 & 4.2 \\
\hline F_AS17 & 197.1 & 77.5 & 30.7 & 5.7 \\
\hline F_AS18 & 122.6 & 68.5 & 32.7 & 2.5 \\
\hline F_AS19 & 159.9 & 75.8 & 28.0 & 4.7 \\
\hline F_AS20 & 164.2 & 77.8 & 25.9 & 5.9 \\
\hline F_AS21 & 151.4 & 76.2 & 26.9 & 5.0 \\
\hline F_AS22 & 144.4 & 78.0 & 28.9 & 6.9 \\
\hline F_AS23 & 141.1 & 77.5 & 27.0 & 5.8 \\
\hline F_AS24 & 133.6 & 75.8 & 24.7 & 4.8 \\
\hline D_AS25 & 150.1 & 80.0 & 30.0 & 4.3 \\
\hline D_AS26 & 146.0 & 81.0 & 27.9 & 6.2 \\
\hline D_AS27 & 146.5 & 83.7 & 26.6 & 5.4 \\
\hline D_AS28 & 158.7 & 81.2 & 29.0 & 4.5 \\
\hline D_AS29 & 155.8 & 80.2 & 26.0 & 6.7 \\
\hline D_AS30 & 168.7 & 79.3 & 34.3 & 5.1 \\
\hline D_AS31 & 161.2 & 81.3 & 31.3 & 5.0 \\
\hline D_AS32 & 167.2 & 83.5 & 27.6 & 6.4 \\
\hline D_AS33 & 177.8 & 81.3 & 28.0 & 8.4 \\
\hline D_AS35 & 155.0 & 81.7 & 26.2 & 7.2 \\
\hline D_AS36 & 171.8 & 85.7 & 28.5 & 7.5 \\
\hline D_AS37 & 157.1 & 81.2 & 31.3 & 5.3 \\
\hline F_AS38 & 154.2 & 80.8 & 30.1 & 6.0 \\
\hline D_AS39 & 131.0 & 80.5 & 29.5 & 5.3 \\
\hline F_AS40 & 153.7 & 80.2 & 29.8 & 5.9 \\
\hline
\end{tabular}

Phenotypic means

$\begin{array}{lllll}\text { Flint } & 147.0 \pm 18.5 & 76.2 \pm 3.4 & 28.4 \pm 2.9 & 4.7 \pm 1.1 \\ \text { Dent } & 158.4 \pm 13.4 & 81.6 \pm 2.6 & 28.7 \pm 2.3 & 6.0 \pm 1.4 \\ \text { Overall } & 152.0 \pm 17.3 & 78.6 \pm 4.1 & 28.5 \pm 2.6 & 5.3 \pm 1.4\end{array}$

Variance components

$\begin{array}{lllll}\text { Lines } & 8.3^{* *} & 12.6^{* *} & 7.00^{* *} & 5.5^{* *} \\ \text { Environments } & 44.0^{* *} & 133.3^{* *} & 30.3^{* *} & 2.5 \\ \text { LXE } & 3.5^{* *} & 6.2^{* *} & 2.7^{* *} & 4.0^{* *}\end{array}$


Table 1: Phenotypic means, variance components, and heritabilities for four agronomic traits across four environments. (Continued)

\begin{tabular}{lllll}
\hline LSD5 & 16.8 & 3.3 & 2.7 & 1.64 \\
& & & & \\
Heritability\% and Cl interval & & & \\
Heritability\% & 88.0 & 92.0 & 85.7 & 81.9 \\
$90 \% \mathrm{Cl}$ on $h^{2}$ & $78.9-92.6$ & $85.7-95.3$ & $74.9-91.3$ & $68.2-88.9$
\end{tabular}

These lines are the same 40 lines (except D_AS34) used by Andersen et al. [36]

Flint- and dent lines are denoted by $F$ and $D$ prefixes, respectively. PHT: plant height $(\mathrm{cm})$; DTS: days to silking; DMC: dry matter content of stover; DMY: dry matter yield of stover (tons per hectare)

LSD5: least significant difference at $5 \%$ level between lines

$\mathrm{Cl}$ : confidence interval

*, ${ }^{* *}$ significant at $5 \%$ and $1 \%$ level, respectively.

with $r^{2}>0.89$, which explained $23.5 \%$ of the phenotypic variation for DMC. Another indel, which starts at position 663 in this locus explained $25.8 \%, 18.5 \%$, and $10.5 \%$ of variation for PHT, DTS, and DMC, respectively. At the $4 C L 1$ locus, two indels (starting at position 454 and 810 ) were both associated with DTS, and explained $20.2 \%$ and $6 \%$ of the phenotypic variation, respectively. These two indels both resulted in reading frame shift, with one of those being a singleton. Lines with an Adenine insertion at position 454 silked on average three days earlier than the remaining lines. The COMT gene has been shown to strongly affect cell wall digestibility and plant height. However, only one polymorphism was detected for associations with DTS. The indel in the 3'UTR was detected only by GLM and explained $10.3 \%$ of the phenotypic variation for DTS. Finally, one trait association was detected at the $F 5 H$ locus, which was a missense substitution at position 65 and explained $22.4 \%$ of the phenotypic variation for DTS.
Pleiotropic polymorphisms affecting biomass yield and forage quality

In order to increase the chance of finding potential pleiotropic QTP affecting both biomass yield-related and digestibility traits, associations of monolignol biosynthetic genes [[35,36], Brenner et al.: Polymorphisms in $O$ methyltransferase genes are associated with stover cell wall digestibility in European maize (Zea mays L.), submitted] were determined without multiple test adjustment. In our study, two additional trait associations were detected only by MLM, one of which was an association between a synonymous SNP in the COMT gene and PHT, the other one was between a tight LD group in the $F 5 H$ gene (two SNPs at position 5 and 6 in complete LD) and DMY. Despite of these relaxed statistical test conditions, only two polymorphisms in 10 monolignol biosynthetic genes were associated with both biomass yield-related and cell wall digestibility traits. The indel starting at position 810 , resulting in a reading frame shift in the $4 C L 1$ gene, was associated with IVDOM [36] and DTS identified by both GLM and MLM. It was also associated with NDF identified by GLM [36]. The tight LD group with two SNPs in complete LD in the $F 5 H$ gene, resulting in a substitution from Proline to Arginine, was associated with both DMY (by MLM) and NDF (by GLM) [36]. In addition, the tight LD group in the $P A L$ gene showing association with DTS in our study was also associated with NDF [35]. However, the association between this LD group and NDF was only detected when population structure was not considered. In summary, no pleiotropic polymorphisms associated with DNDF and DMY or PHT were identified.

Table 2 Phenotypic and genotypic (italics) correlations between forage quality and yield-related traits.

\begin{tabular}{|c|c|c|c|c|c|c|c|}
\hline & DTS & DMC & DMY & WSC & IVDOM & NDF & DNDF \\
\hline \multirow[t]{2}{*}{ PHT } & $0.64^{* *}$ & -0.17 & $0.64^{* *}$ & 0.24 & -0.31 & 0.06 & $-0.45^{* *}$ \\
\hline & $0.62^{* *}$ & -0.17 & $0.69^{* *}$ & $0.24^{*}$ & $-0.35^{* *}$ & 0.11 & $-0.47^{* *}$ \\
\hline \multirow[t]{2}{*}{ DTS } & & -0.13 & $0.72^{* *}$ & 0.17 & -0.17 & 0.08 & -0.26 \\
\hline & & -0.09 & $0.78^{* *}$ & 0.14 & $-0.22^{*}$ & 0.17 & $-0.28^{*}$ \\
\hline \multirow[t]{2}{*}{ DMC } & & & $-0.35^{*}$ & $-0.51^{* *}$ & $-0.39^{*}$ & $0.61^{* *}$ & -0.15 \\
\hline & & & $-0.37^{* *}$ & $-0.56^{* *}$ & $-0.40^{* *}$ & $0.66^{* *}$ & $-0.17^{*}$ \\
\hline \multirow[t]{2}{*}{ DMY } & & & & $0.44^{* *}$ & 0.00 & -0.23 & -0.22 \\
\hline & & & & $0.47^{* *}$ & -0.03 & $-0.23^{*}$ & $-0.24^{*}$ \\
\hline
\end{tabular}

** Significant at $\mathrm{P}=0.01$. Significant at $\mathrm{P}=0.05$.

PHT: plant height in $\mathrm{cm}$

DTS: days from sowing to silking

DMC: \% dry matter content of stover

DMY: Dry matter yield of stover in tons per hectare

WSC: Water soluble carbohydrates

IVDOM: In vitro digestibility of organic matter

NDF: Neutral detergent fiber

DNDF: Digestibility of neutral detergent fiber 
Table 3 Associations between individual polymorphisms or LD groups and biomass yield and agronomic traits.

\begin{tabular}{|c|c|c|c|c|}
\hline Gene & Position & Associated trait & $\mathrm{R} \wedge 2 \%$ & Identified by \\
\hline$\overline{P A L}$ & $947-1655^{L D, 1}$ & DTS & $7.4 \%$ & $\mathrm{GLM}^{*}, \mathrm{MLM}^{* *}$ \\
\hline $4 C L 2$ & $192,217^{L D, 2}$ & PHT & $14.3 \%$ & $\mathrm{GLM}^{*}, \mathrm{MLM}^{*}$ \\
\hline COMT & 2358 & DTS & $10.3 \%$ & $\mathrm{GLM}^{*}$ \\
\hline $\mathrm{F} 5 \mathrm{H}$ & 65 & DTS & $22.4 \%$ & $G L M^{* *}$ \\
\hline \multirow[t]{2}{*}{$4 C L 1$} & 454 & DTS & $20.2 \%$ & $\mathrm{GLM}^{*}, \mathrm{MLM}^{*}$ \\
\hline & 810 & DTS & $6.0 \%$ & $\mathrm{GLM}^{*}, \mathrm{MLM}^{* *}$ \\
\hline \multirow[t]{4}{*}{ CCOAOMT2 } & $75,144,406^{L D, 3}$ & DMC & $23.5 \%$ & $\mathrm{GLM}^{*}, \mathrm{MLM}^{*}$ \\
\hline & 663 & PHT & $25.8 \%$ & $\mathrm{GLM}^{*}$ \\
\hline & 663 & DTS & $18.5 \%$ & $\mathrm{GLM}^{*}, \mathrm{MLM}^{* *}$ \\
\hline & 663 & DMC & $10.5 \%$ & $\mathrm{GLM}^{*}, \mathrm{MLM}^{* *}$ \\
\hline
\end{tabular}

Positions of trait associated polymorphisms are presented according to public reference sequences.

LD linkage group in a linkage block; ${ }^{1}$ the LD group contains 17 polymorphisms in complete LD in PAL and 947 and 1655 are the first and last polymorphisms; ${ }^{2}$ the LD group contains two polymorphisms which are in complete LD; ${ }^{3}$ the LD group contains three polymorphisms with $r^{2}>0.89$. Associations identified by GLM were after controlling multiple testing, while those identified by MLM were not. Polymorphism positions are denoted by the position in our alignment; $R^{2} \%$ is the proportion of phenotypic variance explained by the detected polymorphisms/LD group; ${ }^{*}$ and ${ }^{* *}$ mean $\mathrm{P}<0.05$ and $\mathrm{P}<0.01$, respectively.

4CL: 4-coumarate:CoA ligase, $\mathrm{C} 3 \mathrm{H}$ : p-coumarate 3-hydroxylase, $\mathrm{C} 4 \mathrm{H}$ : cinnamate 4-hydroxylase, $C A D$ : cinnamyl alcohol dehydrogenase, $C \mathrm{COAOMT}$ : caffeoyl-CoA Omethyltransferase, COMT: caffeic acid O-methyltransferase, F5H: ferulate 5-hydroxylase; PHT: plant height in cm; DTS: days from sowing to silking; DMC: \% dry matter content of stover; DMY: dry matter yield of stover in tons per hectare

\section{Discussion and conclusion}

\section{Impact of the association analysis method on QTP} identification

Two statistical approaches (GLM and MLM) were employed as in previous association studies for better comparison across quality [[35,36], Brenner et al:: Polymorphisms in $\mathrm{O}$-methyltransferase genes are associated with stover cell wall digestibility in European maize (Zea mays L.), submitted] and yield-related traits (this study). In those former studies, the same line panel, gene sequences, and marker data have been used. Inclusion of both population structure and relative kinship reduces the number of false positive associations compared to including population structure alone [40]. In the present study, most of the associations identified for biomass yield and other agronomic traits by GLM were also identified by MLM, although none of the associations identified by MLM remained significant after controlling for multiple testing. Therefore, we can not exclude the possibility that familiar relatedness resulted in false positives. However, this result might also suggest that inclusion of relative kinship information might in some cases mask genuine associations, comparable to likely false negatives of flowering time caused by inclusion of population structure for the Dwarf8 gene in European maize [41]. In this example, likely true effects of QTP on flowering time were confounded with presence of one particular allele set in flint, the other in dent lines.

\section{Characterization of polymorphisms associated with biomass yield and agronomic traits}

We compared trait-associated (27) with not-associated polymorphisms (255) within the 10 monolignol biosynthetic genes regarding (i) the distribution among SNPs and indels, and (ii) polymorphisms among coding and non-coding sequences. Based on Chi-square tests, traitassociated polymorphisms for biomass yield-related traits were not preferentially due to either SNPs or indels, and not primarily located in either coding or non-coding gene regions.

Polymorphisms in conserved motifs with impact on protein function or abundance are more likely candidates for causative QTPs [42]. Within the PAL gene in our study, 1 out of 17 polymorphisms in the LD group associated with DTS was located within a possible bipartite RAV1 binding site $[43,44]$. RAV1 has been suggested as a negative regulator of plant growth and development [45]. In addition, five polymorphisms in the same LD group were located within Dof-like motifs [43]. Dof transcription factors play a critical role in plant growth and development [46]. Those six polymorphisms are more likely candidates for causative QTPs, whereas the remaining 11 significant associations within the same LD group are more likely due to linkage. To pinpoint causative polymorphisms, further dissection based on additional alleles at low LD is required. In the CCOAOMT2 gene, a 40-60 bp indel at position 663 was just six base pairs upstream of a 3' splicing donor site, spanning a potential "branching site" for splicing. Consequently, this indel might affect splicing and in this way interfere with the mRNA sequence and function of CCOAOMT2. Moreover, this indel also spanned part of a bipartite RAV1 binding site [43]. Interestingly, this site was associated with three biomass yield-traits. Although LD decay was rapid in CCoAOMT2, the indel and two SNPs, which are at positions 75, 144, and 406, respectively, were tightly linked $\left(r^{2}>0.89\right)$. The indel resulted in two amino acid (Asparagine and Glycine) 
Table 4 Polymorphism character and position in reference sequence.

\begin{tabular}{llll}
\hline Gene & Position & Polymorphism & Position in reference sequence \\
\hline PAL & 947 & Intron SNP & TTAGAGACGATCGCAATCCA(C/T) \\
$4 C L 2$ & 1652,1655 & Intron SNP & CCTTGTGCGTGGCTCCC(T/C)TT(C/T) \\
& 192 & synonymous SNP & TACTGCTTCGGGAGATGGG(T/C) \\
COMT & 217 & Val to lle SNP & TGGCGGAGCGGGGTGCTG(G/A) \\
F5H & 2358 & $3^{\prime}$ UTR indel & CGCCGTCGTCGTCTTCTTCT(+/-) \\
$4 C L 1$ & 65 & Leu to Pro SNP & ACGCGCGACAATATCAAGGC(T/C) \\
& 454 & Exon indel & TTCGTCGGCAAGGTGGGGG(+/-) \\
CCOAOMT2 & $810^{5}$ & Exon indel & GCTGTGCGGGAGCGCGCGG(+/-) \\
& 75 & Exon Indel & CAGGCCAACGGCAACGGCAA(+/-) \\
& 144 & synonymous SNP & CTGCTCAAGAGCGACGACCT(C/G) \\
& 406 & Intron SNP & ACCGAGATCTGAGAACGAAC(A/G) \\
& 663 & Intron indel & CCTAGGATCTTAACCACCCC(+/-)
\end{tabular}

Polymorphism character and position in reference sequence. (N/N): SNP substitution; (+/-): indel; s: singleton; M73235, AY323238, AY279014, AX204867, AX204868, and AX204869 were used as reference sequences for COMT, CCOAOMT1, CCOAOMT2, 4CL1, 4CL2, and F5H respectively. The reference sequences for $P A L$ are the conserved sequences before each polymorphism in our alignment.

deletions compared with the CCOAOMT2 allele of maize inbred line F2 (NCBI accession number AY279014.1). The other two SNPs were either synonymous or intron located SNPs. Thus, the indel is a more promising candidate QTP compared to the other two SNPs. Two DTS associated polymorphisms in $4 C L 1$, which were both single nucleotide indels, led to frame shift mutations. One indel starting at position 810 introduced a premature stop [36]. The other indel changed the peptide sequence substantially, since it is located close to the transcription initiation site. In $4 C L 2$, two polymorphisms in complete LD were associated with PHT. One of them changed the amino acid sequence and is, therefore, a more likely candidate QTP. In the $F 5 H$ gene, Leucine to Proline and Proline to Arginine substitutions, were associated with DTS and DMY, respectively. Both are expected to change protein structure dramatically based on the Blosum-62 substitution matrix [47]. Proline is very different from other amino acids due to its aliphatic side chain bonded to both nitrogen and $\alpha$-carbon atoms. In summary, some of the above mentioned trait associated polymorphisms or LD groups likely change protein sequence and expression dramatically, and are consequently the most likely QTPs affecting agronomic traits. However, future studies with maize populations with very low LD or alternative approaches are required for validation.

\section{Pleiotropic effects of monolignol biosynthetic genes}

Besides biosynthesis of lignin monomers, the monolignol biosynthetic pathway is involved in biosynthesis of salicylates, coumarins, hydroxycinnamic amides, pigments, UV light protectants, antioxidants, and flavonoids [48]. Jone [49] concluded that phenylpropanoid compounds are involved in controlling plant development, growth, xylogenesis, and flowering. For example, chalcone and naringenin, two intermediates in the phenylpropanoid metabolism in plants, inhibit $4 C L$ activity [50] and suppress the growth of at least 20 annual plant species including maize [51]. Moreover, mutants in genes coding for $\mathrm{C} 3 \mathrm{H}, \mathrm{C} 4 \mathrm{H}, \mathrm{PAL}$, CCoAOMT1, CCR1 and HCT show effects on plant growth [19-26]. This is likely due to redirection of metabolic flux and accumulation of compounds, like naringenin, flavonoids, chalcone, which have the potential to perturb hormone homeostasis and ultimately affect plant growth.

In our study, polymorphisms affecting both biomass yield and cell wall digestibility were identified in six monolignol biosynthetic genes (encoding for COMT, CCoAOMT2, 4CL1, 4CL2, F5H, and PAL). These findings indicate that at least some of the monolignol biosynthetic genes act pleiotropically on both lignin content or composition and biomass yield or other agronomic traits. However, only two polymorphisms, the indel at position 810 in the $4 C L 1$ gene and the LD group with SNPs resulting in substitution from Proline to Arginine [36] in the $F 5 H$ gene, were found to be associated with both biomass yield and cell wall digestibility traits without controlling multiple testing. After controlling multiple testing, only the indel in the $4 C L 1$ gene was associated with both DTS and IVDOM. Thus, the majority of QTPs identified in our study affected only one of the two groups of traits. Intragenic linkage of respective QTPs was more abundant than pleiotropic QTPs. According to our findings, most QTPs for both groups of traits are expected to segregate independently in germplasms with low LD.

Another important implication from our results is, that pleiotropy identified by comparison of wild-type with knock-out alleles, might in several cases turn out to be due to close linkage of intragenic QTPs with effects on different pathways and traits. An example is the well-studied 
Dwarf8 gene. This gene has been shown to affect plant height, when comparing mutant and wild type alleles [52]. However, association analyses with a range of wildtype alleles revealed candidate QTPs for flowering time, but not for plant height [37]. In Dwarf8, the DELLA domain is thought to affect plant height [52], while other polymorphisms affect flowering time. The DELLA domain was conserved in the 92 inbred lines used for an association analysis [37]. Similarly, previous $b m 3$ mutant studies implied that the COMT coding gene acts pleiotropically on both forage quality and yield characters. However, after adjustment for multiple testing only one polymorphism was associated with DTS in our analysis, whereas eight different polymorphisms were associated with DNDF [Brenner et al:: Polymorphisms in $O$-methyltransferase genes are associated with stover cell wall digestibility in European maize (Zea mays L.), submitted]. Since earlier reports on pleiotropy of $\mathrm{bm}$ mutations were based on isogenic lines, another explanation might be closely linked genes in introgressed donor segments affecting either quality or yield characters.

\section{Implications for plant breeding}

Although the genetic correlation between DNDF and DMY was significant $(\mathrm{P}=0.05)$, it was very low $(\mathrm{r}=$ $-0.24)$ in these 39 inbred lines. Hence, it is very likely that the majority of genes affecting either biomass yield or cell wall digestibility traits are different. Our results support that monolignol biosynthetic genes affect both biomass yield-related and cell wall digestibility traits. Intragenic linkage of QTPs was the more frequent cause for "pleiotropy" compared to pleiotropic polymorphisms. No QTP in our study was associated with PHT and DNDF, or DMY and DNDF. Considering these correlations and association data together, we conclude that breeders can employ optimal wildtype alleles for monolignol biosynthetic genes to improve cell wall digestibility, without penalty on DMY.

\section{Methods}

\section{Plant materials}

A panel of 39 European elite inbred lines including 22 Flint and 17 Dent lines used for forage quality studies [[35,36], Brenner et al.: Polymorphisms in O-methyltransferase genes are associated with stover cell wall digestibility in European maize (Zea mays L.), submitted] were employed in this study. Five lines (AS01 = F7, AS02 $=\mathrm{F} 2, \mathrm{AS} 03=\mathrm{EP} 1, \mathrm{AS} 39=\mathrm{F} 288$, and AS40 = F4) were from the public domain, the remaining inbred lines were provided by KWS Saat AG (Table 1). These lines were selected as extremes with respect to DNDF from a larger set of $>300$ European lines (unpublished data).

\section{Agronomic trials}

Four biomass yield-related traits were evaluated for these 39 lines in Grucking (sandy loam) and Bernburg (sandy loam) in 2002 and 2003, respectively. Field trials were performed as $7^{*} 7$ lattice design with two replications in each environment. 20 plants were planted per plot in single row plots, $3 \mathrm{~m}$ long and $0.75 \mathrm{~m}$ apart. Analysis of forage quality related traits: water soluble carbohydrate (WSC), in vitro digestibility of organic matter (IVDOM), neutral detergent fiber (DNF), and digestibility of neutral detergent fiber (DNDF) have previously been reported [36]. In our study, four biomass yield-related traits PHT, DTS, DMC, and DMY were analyzed. PHT was measured as distance from soil level to the lowest tassel branch after flowering. DTS was measured as days from sowing to silking. Dry matter content (DMC) of stover $(\mathrm{g} / \mathrm{kg})$ (ears were manually removed) was determined 50 days after flowering and dry matter yield (DMY) was measured in tons per hectare.

\section{Phenotypic data analyses}

Mean values, heritability, and variance components of each biomass yield-related trait and correlations between the above mentioned eight traits were calculated in PLABSTAT version 3A [53]. Briefly, analyses of variance were performed for each experiment separately. Adjusted entry means and effective error mean squares were used to compute the combined variances and covariances across environments for each trait. The sums of squares for entries were subdivided into variation among inbred lines, environments, interaction between inbred lines and environments, and error. Variance components were computed for lines and environments, considering them as random effects in the statistical model: Phenotype $=$ effects of lines + effects of environments + effects of lines by environment $(\mathrm{P}=$ mean $+\mathrm{L}+\mathrm{E}+\mathrm{L} \times \mathrm{E})$. F-tests were employed for testing the homogeneity of lines, environments and interactions between lines and environments according to the approximation given by Satterthwaite [54]. Heritabilities $\left(h^{2}\right)$ for each trait were calculated on an entry-mean basis, and confidence intervals for $h^{2}$ were obtained according to Knapp et al. [55]. Phenotypic and genotypic correlations between eight traits were calculated by standard procedures [56].

\section{DNA extraction, amplification, and sequencing}

Leaves of each of the 39 lines were harvested in the greenhouse three weeks after germination for DNA extraction by the Maxi CTAB method [57]. Primers for PCR amplification of $C 4 H, 4 C L 1,4 C L 2, C 3 H, F 5 H, C A D, P A L$, COMT, CCoAMT1, and CCOAMT2, as well as amplification conditions were described elsewhere [[35,36,39], Brenner et al:: Polymorphisms in $O$-methyltransferase genes are associated with stover cell wall digestibility in European maize (Zea mays L.), submitted]. Two overlapping fragments were amplified for $P A L$ and COMT to cover the complete genes, whereas partial gene sequences were obtained for the other genes. Sequences were aligned in CLUSTALW [58] and stored in Nexus format for 
haplotype analysis in DnaSP [59]. Only one member of the $P A L, C 4 H, F 5 H$, and $C A D$ gene families, respectively, was amplified. The reference sequences used for primer design were L77912, AY104175, AX204869, and AJ005702 (GenBank accession number). Primers for COMT and $\mathrm{C} 3 \mathrm{H}$ were designed based on M73235 and AY17051. Two members of the $C C O A O M T$ gene family corresponding to CCoAOMT1 and CCoAOMT2 [60] were amplified. Two members of the $4 C L$ gene family corresponding to the sequences reported by Puigdomenech et al. [61] were amplified.

\section{Population structure and association analysis}

101 publicly available simple sequence repeat markers (SSR) http://www.maizegdb.org/ssr.php, evenly distributed across the whole genome of maize, were employed to genotype the 39 inbred lines. SSR data were used to infer the population structure in Structure 2.0 software $[62,63]$. Individual lines were grouped based on marker profiles by the Bayesian clustering method of Structure 2.0. The membership coefficients for each individual in each subpopulation were calculated with a burn-in length of 50,000 followed by 50,000 iterations and stored in a Q matrix. Inbreds were treated as haploids. Based on these SSR marker data, finer scale relative kinship (K)- Loiselle kinship coefficients [64] between lines were calculated in SPAGeDi [65]. Values on the diagonal of the $\mathrm{K}$ matrix were set as 2 , and negative values in the matrix indicating that two individuals were less related than randomly chosen individuals [65] were set to 0 .

Association analyses were carried out using the general linear model (GLM), and mixed linear model (MLM) in TASSEL 2.01 software [41] to test associations between polymorphisms of the 10 monolignol biosynthetic genes and four biomass traits. The threshold for $P$-values was set to 0.05 . In all models, the Q matrix was used to account for overall population structure. 10,000 permutations were used to determine the $P$-value for association of each polymorphism by GLM. The $P$-value adjusted for multiple tests was obtained by a step-down MinP procedure [66], implemented in TASSEL. For MLM, the K matrix was included to account for relative kinship between individuals [41]. Trait associated polymorphisms with $r^{2}>0.85$ and $D^{\prime}>0.9$ were assigned to a tight LD group [67]. The phenotypic variation explained by this tight LD group was considered to be equal to the phenotypic variation of that polymorphism with the largest effect in this region. The False Discovery Rate (FDR) was determined to correct for multiple testing by MLM [68].

Additional file 1: Supplementary table. Haplotype number, average, minimum, and maximum of biomass yield-related trait values for each monolignol biosynthetic gene. Haplotype numbers and inbred lines included in each haplotype group: see [35] for PAL, [36] for 4CL2, 4CL1, $C A D, C 3 H, C 4 H$, and F5H, and [Brenner et al:: Polymorphisms in $\mathrm{O}$ methyltransferase genes are associated with stover cell wall digestibility in European maize (Zea mays L.), submitted] for CCOAOMT1, CCOAOMT2, COMT.

Click here for file

[http://www.biomedcentral.com/content/supplementary/1471-2229-1012-S1.DOC]

\section{Abbreviations}

4CL: 4-coumarate:CoA ligase; $\mathrm{C} 3 \mathrm{H}$ : p-coumarate 3-hydroxylase; $\mathrm{C} 4 \mathrm{H}$ : cinnamate 4-hydroxylase; CAD: cinnamyl alcohol dehydrogenase; CCOAOMT: caffeoyl-CoA O-methyltransferase; COMT: caffeic acid O-methyltransferase; F5H: ferulate 5-hydroxylase; PAL: phenylalanine ammonia-lyase; indel: insertion-deletion polymorphism; LD: linkage disequilibrium; QTP: quantitative trait polymorphism; SNP: single-nucleotide polymorphism; IVDOM: in vitro digestibility of organic matter; DNDF: digestibility of neutral detergent fiber; NDF: neutral detergent fiber; WSC: water soluble carbohydrates; PHT: plant height; DTS: days to silking; DMC: dry matter content; DMY: dry matter yield

\section{Acknowledgements}

We would like to thank KWS Saat AG (Einbeck) and the German ministry for education and science (BMBF) for financial support of the EUREKA project Cerequal. We thank the constructive advice from three anonymous reviewers. YC and EAB are now supported by the RF Baker Center for Plant Breeding at lowa State University. YC was also supported by the interdepartmental genetics graduate program at lowa State University.

\section{Author details}

${ }^{1}$ Department of Agronomy, lowa State University, Ames, lowa 50011, USA. ${ }^{2}$ Interdepartmental Genetics Graduate Program, lowa State University, Ames, lowa 50011, USA. ${ }^{3}$ Department of Agronomy and Plant Breeding, Technical University of Munich, Am Hochanger 2, 85354 Freising-Weihenstephan, Germany. ${ }^{4}$ Department of Genetics and Biotechnology, University of Aarhus, Research Center Flakkebjerg, 4200 Slagelse, Denmark. ${ }^{5}$ KWS Saat AG, Grimsehlstr. 31,37555 Einbeck, Germany.

\section{Authors' contributions}

YC performed the data analysis and prepared the manuscript. IZ carried out allele sequencing. EAB was involved in data analysis. JRA helped with statistical data analysis. MO provided the SSR data. ML has run the field trial. TL coordinated the project and together with YC prepared the manuscript. All authors read and approved the final manuscript.

Received: 4 June 2009

Accepted: 15 January 2010 Published: 15 January 2010

\section{References}

1. Lorenz AJ, Anex RP, Isci A, Coors JG, de Leon N, Weimer PJ: Forage quality and composition measurements as predictors of ethanol yield from maize (Zea mays L.) stover. Biotechnol Biofuels 2009, 2:5.

2. Ralph J, Guillaumie S, Grabber JH, Lapierre C, Barrière Y: Genetic and molecular basis of grass cell-wall biosynthesis and degradability. III. Towards a forage grass ideotype. C R Biol 2004, 327:467-479.

3. Torney F, Moeller L, Scarpa A, Wang K: Genetic engineering approaches to improve bioethanol production from maize. Curr Opin Biotechnol 2007, 18:193-199.

4. Duncan S, Jing Q, Katona A, Kazlauskas RJ, Schilling J, Tschirner U, Wafa Aldajani W: Increased Saccharification Yields from Aspen Biomass Upon Treatment with Enzymatically Generated Peracetic Acid. Appl Biochem Biotechnol 2009.

5. U.S. Department of Energy: Energy Efficiency Renewable Energy.http:// www1.eere.energy.gov/biomass/for_researchers.html.

6. Isci A, Murphy PT, Anes RP, Moore KJ: A rapid simultaneous saccharification and fermentation (SSF) technique to determine ethanol yields. Bioenerg Res 2008, 1:163-169.

7. Grabber JH, Ralph J, Lapierre C, Barrière Y: Genetic and molecular basis of grass cell-wall degradability. I. Lignin-cell wall matrix interactions. $C R$ Biol 2004, 327:455-465. 
8. Fontaine $A S$, Bout $S$, Barrière $Y$, Vermerris $W$ : Variation in cell wall composition among forage maize (Zea mays L.) inbred lines and its impact on digestibility: analysis of neutral detergent fiber composition by pyrolysis-gas chromatography-mass spectrometry. J Agric Food Chem 2003, 51:8080-8087.

9. Corredor DY, Salazar JM, Hohn KL, Bean S, Bean B, Wang D: Evaluation and characterization of forage sorghum as feedstock for fermentable sugar production. Appl Biochem Biotechnol 2009, 158:164-179.

10. Pedersen JF, Vogel KP, Funnell DL: Impact of reduced lignin on plant fitness. Crop Sci 2005, 45:812-819.

11. Barrière $Y$, Argillier $O$ : Brown-midrib genes of maize: a review. Agronomie 1993, 13:865-876.

12. Barrière $Y$, Ralph J, Méchin $V$, Guillaumie $S$, Grabber JH, Argillier $O$, Chabbert B, Lapierre C: Genetic and molecular basis of grass cell wall biosynthesis and degradability. II. Lessons from brown-midrib mutants. C R Biol 2004, 327:847-860.

13. Miller JE, Geadelmann JL: Effect of brown midrib-3 allele on early vigor and growth rate of maize. Crop Sci 1983, 23:510-513.

14. Miller JE, Geadelmann JL, Marten GC: Effect of the brown midrib-allele on maize silage quality and yield. Crop Sci 1983, 23:493-496.

15. Ballard CS, Thomas ED, Tsang DS, Mandebvu P, Sniffen CJ, Endres MI, Carter MP: Effect of corn silage hybrid on dry matter yield, nutrient composition, in vitro digestion, intake by dairy heifers, and milk production by dairy cows. J Dairy Sci 2001, 84:442-452.

16. Cox WJ, Cherney DJR: Influence of brown midrib, leafy, and transgenic hybrids on corn forage production. Agron J 2001, 93:790-796.

17. Casler MD, Pederson JF, Undersander DJ: Forage yield and economic losses associated with the brown-midrib trait in Sudangrass. Crop Sci 2003, 43:782-789.

18. Beck PA, Hutchison S, Gunter SA, Losi TC, Stewart CB, Capps PK, Phillips JM: Chemical composition and in situ dry matter and fiber disappearance of sorghum $\times$ Sudangrass hybrids. J Anim Sci 2007, 85:545-555.

19. Pinçon G, Maury S, Hoffmann L, Geoffroy P, Lapierre C, Pollet B, Legrand M: Repression of $\mathrm{O}$-methyltransferase genes in transgenic tobacco affects lignin synthesis and plant growth. Phytochemistry 2001, 57:1167-1176.

20. Elkind Y, Edwards R, Mavandad M, Hedrick SA, Ribak O, Dixon RA, Lamb CJ: Abnormal plant development and down-regulation of phenylpropanoid biosynthesis in transgenic tobacco containing a heterologous phenylalanine ammonia-lyase gene. PNAS 1990, 87:9057-9061.

21. Leplé JC, Dauwe R, Morreel K, Storme V, Lapierre C, Pollet B, Naumann A, Kang KY, Kim H, Ruel K, Lefèbvre A, Joseleau JP, Grima-Pettenati J, De Rycke R, Andersson-Gunnerås S, Erban A, Fehrle I, Petit-Conil M, Kopka J, Polle A, Messens E, Sundberg B, Mansfield SD, Ralph J, Pilate G, Boerjan W: Downregulation of cinnamoyl-coenzyme $A$ reductase in poplar: multiple-level phenotyping reveals effects on cell wall polymer metabolism and structure. Plant Cell 2007, 19:3669-3691.

22. Mir Derikvand M, Sierra JB, Ruel K, Pollet B, Do CT, Thévenin J, Buffard D, Jouanin L, Lapierre C: Redirection of the phenylpropanoid pathway to feruloyl malate in Arabidopsis mutants deficient for cinnamoyl-CoA reductase 1. Planta 2008, 227:943-956.

23. Franke R, Humphreys JM, Hemm MR, Denault JW, Ruegger MO, Cusumano JC, Chapple C: The Arabidopsis REF8 gene encodes the 3hydroxylase of phenylpropanoid metabolism. Plant J 2002, 30:33-45.

24. Schilmiller AL, Stout J, Weng JK, Humphreys J, Ruegger MO, Chapple C: Mutations in the cinnamate 4-hydroxylase gene impact metabolism, growth and development in Arabidopsis. Plant J 2009, 60:771-782.

25. Do $C T$, Pollet $B$, Thévenin J, Sibout $R$, Denoue D, Barrière $Y$, Lapierre $C$, Jouanin L: Both caffeoyl Coenzyme A 3-O-methyltransferase 1 and caffeic acid $O$-methyltransferase 1 are involved in redundant functions for lignin, flavonoids and sinapoyl malate biosynthesis in Arabidopsis. 2007, 226:1117-1129.

26. Besseau S, Hoffmann L, Geoffroy P, Lapierre C, Pollet B, Legrand M: Flavonoid accumulation in Arabidopsis repressed in lignin synthesis affects auxin transport and plant growth. Plant Cell 2007, 19:148-162.

27. Wolf DP, Coors JG, Albrecht KA, Undersander DJ, Carter PR: Agronomic evaluations of maize genotypes selected for extreme fiber concentrations. Crop Sci 1993, 33:1359-1365.

28. Weller RF, Phipps RH, Cooper A: The effect of the brown midrib-3 gene on the maturity and yield of forage maize. Grass Forage Sci 1985, 40:335-339.
29. He X, Hall MB, Gallo-Meagher M, Smith RL: Improvement of forage quality by downregulation of maize O-methyltransferase. Crop Sci 2003, 43:2240-2251

30. Hu WJ, Harding SA, Lung J, Popko JL, Ralph J, Stokke DD, Tsai CJ, Chiang VL: Repression of lignin biosynthesis promotes cellulose accumulation and growth in transgenic trees. Nat Biotechnol 1999, 17:808-812.

31. Guillaumie S, San-Clemente $H$, Deswarte C, Martinez $Y$, Lapierre C, Murigneux A, Barrière Y, Pichon M, Goffner D: MAIZEWALL. Database and developmental gene expression profiling of cell wall biosynthesis and assembly in maize. Plant Physiol 2007, 143:339-363.

32. Raes J, Rohde A, Christensen JH, Peer Van de Y, Boerjan W: Genome-wide characterization of the lignification toolbox in Arabidopsis. Plant Physiol 2003, 133:1051-1071.

33. Rösler J, Krekel F, Amrhein N, Schmid J: Maize phenylalanine ammonialyase has tyrosine ammonia-lyase activity. Plant Physiol 1997, 113:175-179.

34. Guillet-Claude C, Birolleau-Touchard C, Manicacci D, Fourmann M, Barraud S, Carret V, Martinant JP, Barrière Y: Genetic diversity associated with variation in silage corn digestibility for three O-methyltransferase genes involved in lignin biosynthesis. Theor App/ Genet 2004, 110:126-135.

35. Andersen JR, Zein I, Wenzel G, Krützfeldt B, Eder J, Ouzunova M, Lübberstedt T: High levels of linkage disequilibrium and associations with forage quality at a phenylalanine ammonia-lyase locus in European maize (Zea mays L.) inbreds. Theor App/ Genet 2007, 114:307-319.

36. Andersen JR, Zein I, Wenzel G, Darnhofer B, Eder J, Ouzunova M, Lübberstedt T: Characterization of phenylpropanoid pathway genes within European maize (Zea mays L.) inbreds. BMC Plant Biol 2008, 8(2).

37. Thornsberry JM, Goodman MM, Doebley J, Kresovich S, Nielsen D, Buckler ES: Dwarf8 polymorphisms associate with variation in flowering time. Nat Genet 2001, 28:203-204.

38. Roussel V, Gibelin C, Fontaine AS, Barrière Y: Genetic analysis in recombinant inbred lines of early dent forage. II. QTL mapping for cell wall constituents and cell wall digestibility from per se value and top cross experiments. Maydica 2002, 47:9-20.

39. Zein I, Wenzel G, Andersen JR, Lübberstedt T: Low level of linkage disequilibrium at the COMT (caffeic acid O-methyltransferase) locus in European maize (Zea mays L.). Genet Resour Crop Ev 2007, 54:139-148.

40. Yu J, Pressoir G, Briggs WH, Vroh Bi I, Yamasaki M, Doebley JF, McMullen MD, Gaut BS, Nielsen DM, Holland JB, Kresovich S, Buckler ES: A unified mixed-model method for association mapping that accounts for multiple levels of relatedness. Nat Genet 2006, 38:203-208.

41. Andersen JR, Schrag T, Melchinger AE, Zein I, Lübberstedt T: Validation of Dwarf8 polymorphisms associated with flowering time in elite European inbred lines of maize (Zea mays L.). Theor Appl Genet 2005, 111:206-217.

42. Rebbeck TR, Spitz M, Wu X: Assessing the function of genetic variants in candidate gene association studies. Nat Rev Genet 2004, 5:589-597.

43. MOTIF Search. http://motif.genome.jp/.

44. Kagaya Y, Ohmiya K, Hattori T: RAV1, a novel DNA-binding protein, binds to bipartite recognition sequence through two distinct DNA-binding domains uniquely found in higher plants. Nucleic Acids Res 1999, 27:470-478.

45. Hu YX, Wang YX, Liu XF, Li JY: Arabidopsis RAV1 is down-regulated by brassinosteroid and may act as a negative regulator during plant development. Cell Res 2004, 14:8-15.

46. Yanagisawa S: Dof domain proteins: plant-specific transcription factors associated with diverse phenomena unique to plants. Plant Cell Physiol 2004, 45:386-391.

47. Berg JM, Tymoczko JL, Stryer L: Biochemistry WH Freeman and Company, sixth 2007, 169.

48. Dixon RA, Palva N: Stress-induced phynylpropanoid metabolism. Plant cell 1995, 7:1085-1097.

49. Jones DH: Phenylalanine ammonia-lyase: regulation of its induction and its role in plant development. Phytochemistry 1984, 23:1349-1359.

50. Yun MS, Tateuchi N, Deng F, Yogo Y: Distribution of 4-coumarate: CoA ligase isozymes in rice, maize and soybean and their inhibition by some chemicals. J Weed Sci Technol 2001, 46(Suppl):228-229, (in Japanese).

51. Chen WJ, Yun MS, Deng F, Yogo Y: Effects of root-applied naringenin and chalcone on the growth of annual plants. Weed Biol Manage 2004, 4:235-238

52. Peng J, Richards DE, Hartley NM, Murphy GP, Devos KM, Flintham JE, Beales J, Fish LJ, Worland AJ, Pelica F, Sudhakar D, Christou P, Snape JW, 
Gale MD, Harberd NP: 'Green revolution' genes encode mutant gibberellin response modulators. Nature 1999, 400:256-261.

53. Utz HF: PLABSTAT: a computer program for statistical analysis of plant breeding experiments. Institute of Plant Breeding, Seed Science and Population Genetics, University of Hohenheim, Stuttgart, Germany 2003.

54. Satterthwaite FE: An approximate distrubition of estimates of variance components. Biom Bull 1946, 2:110-114.

55. Knapp SJ, Stroup WW, Ross WM: Exact confidence intervals for heritablity on a progeny mean basis. Crop Sci 1985, 25:192-196.

56. Mode CJ, Robinson HF: Pleitropism and the genetic variance variance and covariance. Biometrics 1959, 15:518-537.

57. Saghai-Maroof MA, Soliman KM, Jorgensen RA, Allard RW: Ribosomal DNA spacer-length polymorphisms in barley: Mendelian inheritance, chromosomal location, and population dynamics. PNAS 1984, 81:8014-8018.

58. Thompson JD, Higgins DG, Gibson TJ: CLUSTAL W: improving the sensitivity of progressive multiple sequence alignment through sequence weighting, positions-specific gap penalties and weight matrix choice. Nucleic Acids Res 1994, 22:4673-4680.

59. Rozas J, Sánchez-DelBarrio JC, Messeguer X, Rozas R: DnaSP, DNA polymorphism analyses by the coalescent and other methods. Bioinformatics 2003, 19:2496-2497.

60. Civardi L, Rigau J, Puigdomenech P: Nucleotide sequence of two CDNAs coding for caffeoyl-coenzyme A O-methyltransferase (CCOAOMT) and study of their expression in Zea mays. Plant Physiol 1999, 120:1026-1113.

61. Puigdomenech PC, Perez P, Murigneux A, Martinant JP, Tixier MH, Rigau J, Civardi L, Maes T: Identifying genes associated with a qtI corn digestibility locus. Patent WO 0155395-A 1, 32001.

62. Pritchard JK, Stephens M, Donnelly P: Inference of Population Structure Using Multilocus Genotype Data. Genetics 2000, 155:945-959.

63. Falush D, Stephens M, Pritchard JK: Inference of population structure using multilocus genotype data: linked loci and correlated allele frequencies. Genetics 2003, 164:1567-1587.

64. Loiselle BA, Sork VL, Nason J, Graham C: Spatial genetic structure of a tropical understory shrub, Psychotria officinalis (Rubiaceae). Am J Bot 1995, 82:1420-1425.

65. Hardy OJ, Vekemans X: SPAGeDi: a versatile computer program to analyse spatial genetic structure at the individual or population levels. Mol Ecol Notes 2002, 2:618-620.

66. Ge Y, Dudoit S, Speed TP: Resampling-based multiple testing for microarray data analysis. Test 2003, 12:1-77.

67. Mizuta I, Satake W, Nakabayashi $Y$, Ito C, Suzuki S, Momose $Y$, Nagai $Y$, Oka A, Inoko H, Fukae J, Saito Y, Sawabe M, Murayama S, Yamamoto M Hattori N, Murata M, Toda T: Multiple candidate gene analysis identifies alpha-synuclein as a susceptibility gene for sporadic Parkinson's disease. Hum Mol Genet 2006, 15:1151-1158.

68. Benjamini $Y$, Hochberg $Y$ : Controlling the false discovery rate: a practical and powerful approach to multiple testing. J R Statist SOC B 1995, 57:289-300.

doi:10.1186/1471-2229-10-12

Cite this article as: Chen et al:: Polymorphisms in monolignol biosynthetic genes are associated with biomass yield and agronomic traits in European maize (Zea mays L.). BMC Plant Biology 2010 10:12.

\section{Submit your next manuscript to BioMed Central and take full advantage of:}

- Convenient online submission

- Thorough peer review

- No space constraints or color figure charges

- Immediate publication on acceptance

- Inclusion in PubMed, CAS, Scopus and Google Scholar

- Research which is freely available for redistribution

Submit your manuscript at www.biomedcentral.com/submit
( Biomed Central 